\title{
“ICMS - Patrimônio Cultural”:um estudo sobre a política pública de preservação cultural do Estado de Minas Gerais com ênfase no processo de Educação Patrimonial
}

\author{
"ICMS - Patrimonio Cultural": un estudio sobre la política pública para \\ la preservación cultural del Estado de Minas Gerais con énfasis en el \\ proceso de Educación Patrimonial
}

\section{"ICMS - Cultural Heritage": a study on the public policy for the cultural preservation of the State of Minas Gerais with emphasis on heritage education process}

\author{
Clésio Barbosa Lemos Júnior
}

Palavras chave:

"ICMS - Patrimônio

Cultural"

Política Pública

Preservação

Educação Patrimonial

Minas Gerais
Resumo:

Uma política pública, em particular, uma política de preservação cultural, só se mostra correta e consequente quando além de contemplar medidas referentes à memória e identidade de um povo, baseia-se amplamente em uma concepção que integra as questões socioeconômicas, técnicas, artísticas e ambientais, articulando-as com as questões de qualidade de vida, meio ambiente e cidadania. Diante desse mote, esse estudo foi organizado a partir da análise da política pública de preservação do patrimônio cultural no Estado de Minas Gerais. Para tanto, o artigo foi estruturado da seguinte forma: primeiramente abordou-se, de maneira sucinta, o histórico que deu origem a lei conhecida como "Lei Robin Hood”, responsável pelo ordenamento da referida política pública. Em um segundo momento tratou-seda especificidade do critério patrimônio cultural, cujo reconhecimento se dá pelo termo "ICMS - Patrimônio Cultural". O processo de educação para o patrimônio cultural, tratado como educação patrimonial, foi abordado na terceira seção do artigo com enfoque nas ações que podem ser desenvolvidas para a efetiva aplicação dessa metodologia educacional. Por fim, algumas considerações foram feitas na tentativa de reforçar a temática e fomentar novas discussões. 


\section{Resumen:}

Políticas públicas, en particular, una política de preservación cultural, si muestra correcta cuando contempla medidas relacionados con la memoria y la identidad de un pueblo y se basa en un diseño que integra los aspectos socioeconómicos, técnicos, artísticos y ambientales, articulados con los problemas de calidad de vida, ambiente y ciudadanía. Teniendo en cuenta esto, este estudio fue organizado a partir del análisis de la política pública de preservación del patrimonio cultural en el Estado de Minas Gerais. De esta manera, el artículo se estructuró como sigue: primera se acercó de la historia que dio origen a la ley conocida como "Robin Hood", responsable de la planificación de dicha política pública. En segundo lugar, se habló de la especificidad de los criterios de patrimonio cultural, cuyo reconocimiento se otorga por "ICMS - Patrimonio Cultural". El proceso de educación patrimonial fue discutido en la tercera sección del artículo con énfasis en acciones que pueden desarrollarse para la aplicación efectiva de esta metodología educativa. Por último, si hace algunas consideraciones en un intento de reforzar el tema y promover nuevas discusiones.
Palabras clave:

"ICMS - Patrimonio

Cultural"

Políticas Públicas

Preservación

Educación Patrimonial

Minas Gerais - Brasil

\section{Keywords:}

"ICMS - Cultural

Heritage"

Public Policy

Preservation

Heritage Education

Minas Gerais - Brazil

\section{Abstract:}

Public policy, in particular, a policy of cultural preservation, if it shows correct when it considers measures related to the memory and the identity of a people and is based on a design that integrates socioeconomic, technical and artistic aspects and environmental, articulated with the problems of quality of life, environment and citizenship. With this in mind, this study was organized based on the analysis of public policy of preservation of the cultural heritage in the State of Minas Gerais. In this way, the article was structured as follows: first came the history that gave rise to the law known as "Robin Hood", responsible for the planning of public policy. Secondly, discussed the specificity criteria of cultural heritage, whose recognition is given by "ICMS Cultural Heritage". The process of patrimonial education was discussed in the third section of the article with an emphasis on actions that can be developed for the effective implementation of this methodology. Finally, if you do some considerations in an attempt to reinforce the theme and promote further discussion. 


\section{"ICMS - Patrimônio Cultural": um estudo sobre a política pública de preservação cultural do Estado de Minas Gerais com ênfase no processo de Educação Patrimonial}

\section{Sobre a "Lei Robin Hood"}

As regras sobre a distribuição do Imposto sobre Circulação de Mercadorias e Serviços (ICMS) estão estabelecidas pelo artigo 158 da Constituição Federal que diz:

Art. 158. Pertencem aos Municípios: I - o produto da arrecadação do imposto da União sobre renda e proventos de qualquer natureza,incidente na fonte, sobre rendimentos pagos, a qualquer título, por eles, suas autarquias e pelas fundações que instituírem e mantiverem; II - cinquenta por cento do produto da arrecadação do imposto da União sobre a propriedade territorial rural, relativamente aos imóveis neles situados, cabendo a totalidade na hipótese da opção a que se refere o art. 153, $\S 4^{\circ}$; III - cinquenta por cento do produto da arrecadação do imposto do Estado sobre a propriedade de veículos automotores licenciados em seus territórios; IV - vinte e cinco por cento do produto da arrecadação do imposto do Estado sobre operações relativas à circulação de mercadorias e sobre prestações de serviços de transporte interestadual e intermunicipal e de comunicação.

Parágrafo único. As parcelas de receita pertencentes aos Municípios, mencionadas no inciso IV, serão creditadas conforme os seguintes critérios:

I - três quartos, no mínimo, na proporção do valor adicionado nas operações relativas à circulação de mercadorias e nas prestações de serviços, realizadas em seus territórios;
II - até um quarto, de acordo com o que dispuser lei estadual ou, no caso dos Territórios, lei federal. (BRASIL, 1988, s/p)

Assim, apreende-se que do valor total arrecadado pelos Estados, 25\% pertence aos municípios (inciso IV), devendo ser repassado, no mínimo três quartos, proporcionalmente ao Valor Adicionado Fiscal (VAF) e o restante de acordo com o estabelecido nas leis estaduais.

No caso do Estado de Minas Gerais, obedecendo ao que estabelece a Constituição, ficou definido pelo Decreto-Lei $N^{\circ}$ 32.771 , de julho de 1991, que a distribuição da cota-parte do ICMS dos municípios obedeceria a três critérios, quais sejam: o Valor Adicionado Fiscal (VAF), os municípios mineradores e compensação financeira por desmembramento de distrito. Contudo, a distribuição do ICMS realizada a partir da definição desses critérios, demonstrava um maior grau de concentração de recursos nos municípios mais desenvolvidos e mais ativos economicamente e, consequentemente, um menor grau de recursos para aqueles municípios menos desenvolvidos e mais pobres.

Diante dessa realidade e na tentativa de amenizar parte dessa discrepância, em 28 de dezembro de 1995 foi sancionada a Lei № 12.040 que visava descentralizar a distribuição do imposto. Essa nova lei trouxe mudança nos critérios para repartir a cota-parte do referido imposto e ficou sendo conhecida como "Lei Robin Hood". Nesse sentido, o seu eixo condutor foi desconcentrar renda e transferir recursos para regiões mais pobres; incentivar a aplicação de recursos municipais nas áreas sociais; induzir os municípios a aumentarem sua arrecadação e a utilizarem com mais eficiência os recursos arrecadados e, por fim, criar uma parceria entre estado e municípios, tendo como objetivo a melhoria da qualidade de vida da população destas regiões. Dessa forma, com os novos critérios estabelecidos pela nova lei foram introduzi- 
das variáveis que modificaram a metodologia de cálculo, logo, modificaram o valor de repasse para os municípios (FJP, 2010)".

A partir de dezembro de 1996 foi publicada a Lei $N^{\circ} 12.428$, alterando a lei anterior. Das alterações propostas por essa legislação destaca-se a diminuição do peso do VAF, assim como a melhoria da participação dos critérios: área geográfica, população, população dos 50 municípios mais populosos, educação, saúde, meio ambiente, produção de alimentos, receita própria e patrimônio cultural.

Essa lei prevaleceu até o ano de 2000 quando entrou em vigor a Lei $\mathrm{N}^{\circ}$ 13.803 de 27 de dezembro, que manteve os critérios e as variáveis da lei anterior, contudo, determinou a redução progressiva da compensação financeira que até então recebiam, de maneira específica, os municípios de Mateus Leme e Mesquita, até a sua extinção a partir de 2004.

A Lei $N^{\circ} 13.803$ preponderou até o ano de 2009quando, após vários debates promovidos pela Assembleia Legislativa do Estado de Minas Gerais, foi aprovada e publicada, em 12 de janeiro, a Lei № 18.030 que até hoje está em vigor. Com a sua aprovação foram promovidas várias mudanças na distribuição da cota-parte do ICMS, dentre elas a inclusão de seis novos critérios de avaliação, a saber: turismo, esportes, municípios sede de estabelecimentos penitenciários, recursos hídricos, ICMS solidário e mínimo per capita. Além desses, incluiu-se também o subcritério denominado "ICMS Ecológico" - mata seca. A nova lei entrou em vigor em janeiro de 2010, contudo, a distribuição realizada com base nos novos critérios somente iniciou a partir de 2011 (FJP, 2010).

Dessa forma, pode-se dizer que a "Lei Robin Hood" dispõe sobre a distribuição da parcela da receita do produto da arrecadação do Imposto sobre Operações Relativas à Circulação de Mercadorias e so- bre Prestações de Serviços de Transporte Interestadual e Intermunicipal e de Comunicação - ICMS - pertencente aos municípios e seus principais objetivos são: (i) reduzir as diferenças econômicas e sociais entre os municípios; (ii) incentivar a aplicação de recursos em áreas de prioridade social; (iii) utilizar com eficiência as receitas próprias e; (iv) descentralizar a distribuição do ICMS. Com relação ao sistema de transferência tratado pela lei entende-se que do montante arrecado de ICMS pelo Estado, 25\% pertence aos municípios (CF 1988, art 158, Inciso IV, parágrafo único). Desses $25 \%, 75 \%$ são distribuídos pelo índice do VAF e os $25 \%$ restantes, de acordo com o que estabelece a referida lei. São beneficiados os municípios mais populosos, os municípios mineradores, os municípios que são sedes de estabelecimentos penitenciários, os que têm combatido a renúncia fiscal e aqueles que investem nas áreas de: educação, saúde, preservação do meio ambiente, produção de alimentos, esportes, turismo e conservação do patrimônio cultural (FJP, 2010).

Acerca dos critérios de distribuição e dos órgãos envolvidos na avaliação desses critérios temos: (i) Valor Adicionado Fiscal (VAF), cujo objetivo é apurar o montante global do movimento econômico do município ficando sob a responsabilidade da Secretaria de Estado da Fazenda (SEF); (ii) Área geográfica, está sob a responsabilidade do Instituto de Geociências Aplicadas (IGA) e sua finalidade é medir a relação percentual entre a área geográfica do município e a área total do Estado; (iii) População, esse critério visa medir a relação percentual entre a população residente no município e a população total do Estado, sua responsabilidade fica a cargo da Fundação João Pinheiro (FJP) e do Instituto Brasileiro de Geografia e Estatística (IBGE); (iv) População dos 50 Municípios mais Populosos, tem como objetivo: contemplar os 50 municípios mais populosos do Estado, a responsabilidade desse critério também fica a cargo da Fundação João Pinheiro (FJP) e do Instituto Brasileiro de Geografia e Estatísti- 
ca (IBGE); (v) Educação, está sob a responsabilidade da Secretaria de Estado da Educação (SEE), tem como objetivo melhorar a capacidade de atendimento das escolas municipais, de forma a absorver todo o potencial do município; (vi) Produção de Alimentos, o objetivo desse item é incentivar a produção de alimentos, considerando-se critérios relativos à área cultivada, ao número de pequenos produtores rurais, ao apoio a produção e comercialização de produtos agrícolas e o apoio institucional das prefeituras ao desenvolvimento agropecuário do município, o órgão envolvido é a Empresa de Assistência Técnica e de Extensão Rural do Estado de Minas Gerais (EMATER); (vii) Patrimônio Cultural, sob a responsabilidade Instituto Estadual do Patrimônio Histórico e Artístico de Minas Gerais (IEPHA) tem como objetivo estimular a preservação das obras de arte, paisagens e conjuntos arquitetônicos importantes para a memória dos municípios; (viii) Meio Ambiente, o objetivo desse critério é estimular a adoção de iniciativas de conservação ambiental através da realização de investimentos em unidades de conservação e na solução de problemas de saneamento, os órgãos envolvidos são a Secretaria de Estado de Meio Ambiente e Desenvolvimento Sustentável (SEMAD), o Instituto Estadual de Florestas (IEF), no subcritério Unidade de Conservação e Mata Seca e a Fundação Estadual de Meio Ambiente (FEAM) no subcritério saneamento; (ix) Saúde, o objetivo desse critério é incentivar o desenvolvimento e manutenção de programas de atendimento à saúde das famílias e o aumento da aplicação per capita de recursos em saúde, os órgãos envolvidos são o Tribunal de Contas do Estado de Minas Gerais (TCEMG), a Secretaria de Estado da Saúde (SES) e a Fundação João Pinheiro (FJP); (x) Receita Própria, sob a responsabilidade do Tribunal de Contas do Estado de Minas Gerais (TCEMG) esse critério tem como objetivo medir a relação percentual entre a receita própria do município, oriunda de tributos de sua competência e as transferências de recursos federais e estaduais recebidas, buscando incentivar o município a aumentar sua arrecadação; (xi) Cota Mínima, o objetivo desse critério é distribuir igualmente entre todos os municípios do Estado a parcela cabível ao respectivo peso - 5,5\%, o órgão envolvido é a Fundação João Pinheiro (FJP); (xii) Municípios Mineradores, visando valorizar os municípios mineradores pela efetiva arrecadação do Imposto Único Mineral (IUM), fixado no exercício de 1988, esse critério está sob a responsabilidade da Secretaria de Estado da Fazenda (SEF); (xiii) Recursos Hídricos, tendo como objetivo beneficiar os municípios que tem área alagada por reservatório de água destinado a geração de energia, esse critério fica a cargo da Secretaria do Estado da Fazenda (SEF) e da Agência Nacional de Energia Elétrica (ANEEL); (xiv) Municípios Sede de Estabelecimentos Penitenciários, com o objetivo de favorecer mais recursos aos municípios que possuem estabelecimentos penitenciários instalados em seu domínio, esse critério está sob a responsabilidade da Secretaria de Estado de Defesa Social (SEDS); (xv) Esportes, visando incentivar a criação e manutenção de programas voltados para o desenvolvimento de atividades esportivas no município, esse critério fica a cargo da Secretaria de Estado de Esportes e Juventude (SEEJ) e da Fundação João Pinheiro (FJP); (xvi) Turismo, tendo como objetivo incentivar a criação e manutenção de programas voltados para o desenvolvimento do potencial turístico do município, esse critério é vinculado à Secretaria de Estado de Turismo (SETUR) e à Fundação João Pinheiro (FJP); (xvii) ICMS Solidário, com o objetivo de proporcionar melhor distribuição dos recursos financeiros, tendo em vista a desigualdade entre os municípios do Estado, esse critério fica sob a tutela da Fundação João Pinheiro (FJP) e do Instituto Brasileiro de Geografia e Estatística (IBGE); (xviii) Mínimo per capita, também com o objetivo de proporcionar melhor distribuição dos recursos financeiros, tendo em vista a desigualdade entre os municípios do Estado, esse critério também fica sob a tutela da Fundação João Pinheiro (FJP) e do Instituto Brasileiro de Geografia e Estatística (IBGE) (FJP, 2009). 
A periodicidade da aferição dos índices de cada um dos critérios é anual, com exceção do critério Produção de alimentos que é semestral, do critério Meio ambiente que é trimestral e do critério Saúde que tem a particularidade de ser mensal para o índice Programa Saúde da Família (PSF)e anual para o índice Saúde per capita. Os repasses são realizados no segundo dia útil de cada semana e os valores são depositados na conta geral das prefeituras municipais.
Visando sintetizar parte das informações dessa seção do trabalho, assim como, para uma melhor compreensão de como vem sendo realizado o repasse aos municípios do Estado de Minas Gerais, foi confeccionada e é apresentada, a seguir, uma tabela intitulada - Repasse de ICMS/MG - onde podem ser vistos os valores percentuais de cada um dos critérios adotados pelo Estado considerando um comparativo entre os anos de 2009, 2010 e a partir de 2011.

\begin{tabular}{|c|c|c|c|}
\hline \multirow[t]{2}{*}{ CRITÉRIOS DE DISTRIBUIÇÃO } & \multicolumn{3}{|c|}{ PERCENTUAIS / EXERCÍCIO } \\
\hline & 2009 & 2010 & a partir de 2011 \\
\hline VAF & 79,68 & 79,68 & 75,00 \\
\hline Área geográfica & 1,00 & 1,00 & 1,00 \\
\hline População & 2,71 & 2,71 & 2,70 \\
\hline População dos 50 municípios mais populosos & 2,00 & 2,00 & 2,00 \\
\hline Educação & 2,00 & 2,00 & 2,00 \\
\hline Produção de alimentos & 1,00 & 1,00 & 1,00 \\
\hline Patrimônio cultural & 1,00 & 1,00 & 1,00 \\
\hline Meio ambiente & 1,00 & 1,00 & 1,10 \\
\hline Saúde & 2,00 & 2,00 & 2,00 \\
\hline Receita própria & 2,00 & 2,00 & 1,90 \\
\hline Cota mínima & 5,50 & 5,50 & 5,50 \\
\hline Municípios mineradores & 0,11 & 0,11 & 0,01 \\
\hline Recursos hídricos & 0,00 & 0,00 & 0,25 \\
\hline Municípios sede de estabelecimentos penitenciários & 0,00 & 0,00 & 0,10 \\
\hline Esportes & 0,00 & 0,00 & 0,10 \\
\hline Turismo & 0,00 & 0,00 & 0,10 \\
\hline ICMS solidário & 0,00 & 0,00 & 4,14 \\
\hline Mínimo "per capita" & 0,00 & 0,00 & 0,10 \\
\hline TOTAL & 100,00 & 100,00 & 100,0 \\
\hline
\end{tabular}

Tabela - Repasse de ICMS/MG FONTE: ALMG e FJP - ADAPTADO 
Conforme especificado anteriormente, a apuração dos índices de cada um dos critérios fica a cargo dos órgãos mencionados, contudo, cabe à Fundação João Pinheiro (FJP) publicar o resultado do julgamento dos itens referentes aos 853 municípios do Estado. Caso os prefeitos e as associações de municípios ou seus representantes não concordem com o resultado publicado, estes poderão impugnar os dados e os índices relativos aos critérios de apuração. O prazo para recurso para todos os índices é de 15 dias, com exceção do índice do VAF, que tem prazo de 30 dias contados a partir da sua publicação (FJP, 2009).

Para efeito ilustrativo segue abaixo um quadro com os valores de transferência feitos aos municípios referentes ao mês de novembro de 2017. Na sua elaboração foram consideradas as transferências globais e o critério patrimônio cultural.

\begin{tabular}{|l|c|}
\hline \multicolumn{1}{|c|}{ DESCRIÇÃO } & VALORES EM REAIS \\
\hline Transferência bruta aos municípios $(\mathrm{I})=(\mathrm{II})+(\mathrm{III})$ & $1.014 .178 .434,02$ \\
\hline 25\% do ICMS arrecadado (II) & $1.001 .943 .824,42$ \\
\hline $2,5 \%$ do IPI-exportação & $12.234 .609,60$ \\
\hline FUNDEB (IV) & $202.835 .663,33$ \\
\hline PASEP (V) & $97.876,75$ \\
\hline Transferência líquida aos municípios $(\mathrm{VI})=(\mathrm{I})-(\mathrm{IV})-(\mathrm{V})$ & $811.244 .893,94$ \\
\hline $75 \%$ repasse pelo VAF & $608.433 .670,46$ \\
\hline $\mathbf{2 5 \%}$ repasse conforme Lei Robin Hood & $\mathbf{2 0 2 . 8 1 1 . 2 2 3 , 4 9}$ \\
\hline \multicolumn{2}{|c|}{} \\
\hline Critério Patrimônio Cultural (1\%) & $\mathbf{2 . 0 2 8 . 1 1 2 , 2 3}$ \\
\hline
\end{tabular}

Quadro - Valores de Transferência

FONTE: DADOS BÁSICOS: BANCO ITAÚ - ELABORAÇÃO FJP/CEPP - ADAPTADO

\section{Sobre o "ICMS - Patrimônio Cultural}

Apresentada como única em todo o país, a "Lei Robin Hood" repassa recursos financeiros para os municípios que preservam a sua memória e a sua produção cultural. Dessa forma, o Estado de Minas Gerais, desde 1995, distribui 1\% dos $25 \%$ dos recursos financeiros provenientes do ICMS para os municípios que implantam políticas públicas de preservação cultural.
Dos requisitos exigidos pelo Instituto Estadual do Patrimônio Histórico e Artístico de Minas Gerais (IEPHA), órgão responsável por receber a documentação dos municípios, para atribuir uma pontuação no critério patrimônio cultural destacam-se: Núcleo Histórico (NH); Conjunto Urbano ou Paisagístico (CP); Bens Imóveis (BI); Bens Móveis (BM); Registro de Bens Culturais Imateriais (RI); Inventário de 
Proteção do Patrimônio Cultural (INV); Educação Patrimonial (EP); Planejamento e Política Municipal de Proteção do Patrimônio Cultural e outras ações (PCL) e Fundo Municipal de Preservação do Patrimônio Cultural (FU); (IEPHA, 2007).

Para fazer jus a uma pontuação nos atributos os municípios devem atender às exigências especificadas pela Deliberação Normativa do Conselho Estadual do Patrimônio Cultural (CONEP). Dentre as reivindicações, o Art. $3^{\circ}$ da atual deliberação define:

Art. 30: Para análise dos atributos, os municípios deverão encaminhar os conjuntos documentais definidos nos Quadros I, II e III indicados a seguir. Os municípios também deverão atender às recomendações da ficha de análise do ano de exercício anterior, quando houver.

1) QUADRO I - GESTÃO

A) Política Municipal de Proteção ao Patrimônio Cultural e Outras Ações: relação de procedimentos a serem documentados e informados sobre a implementação de uma política municipal de proteção do patrimônio cultural local, desenvolvida pelo município no âmbito de uma política cultural; B) Investimentos e Despesas Financeiras em Bens Culturais Protegidos: relação de procedimentos a serem documentados e informados sobre a criação do Fundo Municipal de Preservação do Patrimônio Cultural/FUMPAC e a gestão dos seus recursos e, ainda, sobre investimentos e/ou despesas advindas de outras fontes de financiamento de bens culturais materiais tombados ou inventariados e/ou em bens imateriais registrados.

2) QUADRO II - PROTEÇÃO

A) Inventário de Proteção do Patri- mônio Cultural: relação de procedimentos a serem documentados e informados sobre a elaboração do plano e a execução, pelo município, de Inventário do Patrimônio Cultural; B) Processos de Tombamento de Bens Materiais, na esfera municipal: relação de procedimentos a serem documentados e informados sobre os tombamentos de bens materiais no nível municipal - Núcleo Histórico Urbano; Conjuntos Urbanos ou Paisagísticos localizados em zonas urbanas ou rurais; Bens Imóveis incluídos seus respectivos acervos de bens móveis e integrados, quando houver, e Bens Móveis. Somente processos de tombamento definitivo serão considerados para efeito de pontuação; C) Processos de Registro de Bens Imateriais, na esfera municipal: relação de procedimentos a serem documentados e informados sobre os processos de registro de bens imateriais no nível municipal. Somente processos de registro definitivo serão considerados para efeito de pontuação.

3) QUADRO III - SALVAGUARDA E PROMOÇÃO

A) Laudos Técnicos do Estado de Conservação dos Bens Materiais Protegidos, na esfera municipal: relação de procedimentos a serem documentados sobre os laudos de estado de conservação específicos, os quais informam sobre o efeito do tombamento; B) Relatórios de Implementação das Ações e Execução do Plano de Salvaguarda dos Bens Protegidos por Registro, na esfera municipal: relação de procedimentos a serem documentados e informados sobre os relatórios de implementação das ações de salvaguarda do bem imaterial, os quais informam sobre a continuidade dos procedimentos específicos de cada registro; C) Programas de Educa- 
ção para o Patrimônio nas Diversas Áreas de Desenvolvimento: relação de procedimentos a serem documentados e informados sobre a elaboração de projetos e a realização de atividades de educação patrimonial; D) Difusão: relação de ações de difusão tais como publicações e outras ações advindas de programas de pesquisa e de divulgação do patrimônio cultural do município. (CONEP, 2017: 2-3)

Para aperfeiçoar a compreensão das exigências, assim como, para uma melhor organização da documentação nos arquivos do Instituto, o Art. $4^{\circ}$ da Deliberação Normativa solicita que os documentos sejam encaminhados em pastas assim organizadas:

\begin{tabular}{|c|l|}
\hline QUADROS & \multicolumn{1}{|c|}{ CONJUNTOS DOCUMENTAIS } \\
\hline \multirow{2}{*}{$\begin{array}{c}\text { Quadro I } \\
\text { - Gestão }\end{array}$} & A) Política Municipal de Proteção ao Patrimônio Cultural e Outras Ações \\
\cline { 2 - 2 } & B) Investimentos e Despesas Financeiras em Bens Culturais Protegidos \\
\hline \multirow{3}{*}{$\begin{array}{c}\text { Quadro II } \\
\text { - Proteção }\end{array}$} & A) Inventário de Proteção do Patrimônio Cultural \\
\cline { 2 - 2 } & B) Processos de Tombamento de Bens Materiais, na esfera municipal \\
\cline { 2 - 3 } & C) Processos de Registro de Bens Imateriais, na esfera municipal \\
\hline \multirow{4}{*}{$\begin{array}{c}\text { Quadro III } \\
\text { - Salvaguarda } \\
\text { e Promoção }\end{array}$} & $\begin{array}{l}\text { A) Laudos Técnicos do Estado de Conservação dos Bens Materiais Protegidos, } \\
\text { na esfera municipal }\end{array}$ \\
\cline { 2 - 2 } & dos Bens Protegidos por Registro, na esfera municipal \\
\cline { 2 - 2 } & C) Programas de Educação para o Patrimônio, nas Diversas Áreas de Desenvolvimento \\
\hline & D) Difusão do Patrimônio Cultural \\
\hline
\end{tabular}

FONTE: DELIBERAÇÃO NORMATIVA DO CONEP - Nº 01/2016 E № 03/2017 - CONSOLIDADA

Dessa forma, cada município deve encaminhar para o IEPHA, todo ano, 09pastas referentes aos 03quadros - Gestão, Proteção e Salvaguarda e Promoção. As especificidades exigidas para cada uma das pastas são detalhadas na Deliberação Normativa.

Da primeira versão da lei até hoje, o número de municípios participantes, no critério patrimônio cultural, cresceu mais de $700 \%$. Dos iniciais 104 municípios pontuados em 1996, chegou-se em 2017 com 797 municípios, conforme pode ser visto no quadro ao lado intitulado: ICMS - Patrimônio Cultural. Percebe-se também, no quadro exposto, que existe uma alteração no número de municípios pontuados de um ano para o outro. Isso se dá devido a alguns municípios não cumprirem as exigências da Deliberação Normativa, essa postura desabilita tais municípios a receberem os recursos. 


\begin{tabular}{|c|c|}
\hline \multicolumn{2}{|c|}{ ICMS - PATRIMÔNIO CULTURAL } \\
\hline Ano & Municípios pontuados \\
\hline 1996 & 104 \\
\hline 1997 & 120 \\
\hline 1998 & 166 \\
\hline 1999 & 233 \\
\hline 2000 & 207 \\
\hline 2001 & 232 \\
\hline 2002 & 339 \\
\hline 2003 & 364 \\
\hline 2004 & 468 \\
\hline 2005 & 404 \\
\hline 2006 & 593 \\
\hline 2007 & 643 \\
\hline 2008 & 664 \\
\hline 2009 & 646 \\
\hline 2010 & 710 \\
\hline 2011 & 716 \\
\hline 2012 & 727 \\
\hline 2013 & 689 \\
\hline 2014 & 527 \\
\hline 2015 & 658 \\
\hline 2016 & 746 \\
\hline 2017 & 797 \\
\hline
\end{tabular}

FONTE: IEPHA/MG - ADAPTADO

Outra questão curiosa, porém, infeliz, que pode ser percebida, tem relação com as eleições municipais, ou seja, aparentemente, existe uma tendência de menor participação dos municípios quando estes passam por mudança de gestão, haja vista a transição dos anos de 2012 para 2013, de 2008 para 2009 e de 2004 para 2005.Tal episódio pode ser explicado pelo fato do período de ação e preservação, referência para a pontuação, transcorrer entre 01 de dezembro do ano anterior a 30 de novembro do ano seguinte e, uma vez que, a entrega da documentação deve ser realizada, impreterivelmente, até o dia 10 de dezembro de cada ano, desa- 
fortunadamente, é senso comum, quando há a substituição da equipe administrativa, que a gestão anterior não envie a documentação ao IEPHA, prejudicando tanto a arrecadação quanto a própria política de preservação. Além disso, a maioria das administrações municipais não conta com uma equipe técnica concursada em seu quadro de funcionários, dessa forma, necessita utilizar serviços terceirizados de escritórios especializados, assim, exige-se a abertura de licitação para contratação, que normalmente só acontece depois da nova administração se inteirar dos assuntos do município. Contudo, considerando a totalidade dos 853 municípios do Estado de Minas Gerais conclui-se que atualmente $85,69 \%$ possui políticas públicas de preservação e valorização do patrimônio cultural. (IEPHA, s/d)

Bom seria se pudéssemos acreditar que os 797 municípios que cumpriram seus compromissos com a política pública de preservação do patrimônio cultural, em 2017, assim o fizeram por verdadeiramente conhecerem e reconhecerem o valor dos seus bens culturais. Infelizmente, é sabido que boa parte das administrações públicas municipais implanta a política apenas para arrecadar os recursos financeiros provenientes do critério patrimônio cultural, uma vez que o recurso financeiro é depositado na conta geral das prefeituras de onde sai para pagar os mais variados compromissos e, dificilmente, retorna como investimentos no patrimônio e/ou na manutenção da própria política. No sentido de amenizar essa realidade, desde 2010, a Deliberação Normativa do Conselho Estadual do Patrimônio Cultural (CONEP) solicita aos municípios a criação do Fundo Municipal de Proteção ao Patrimônio Cultural (FUMPAC), cuja finalidade específica é prestar apoio financeiro em caráter suplementar, ou seja, aumentar os benefícios das ações destinadas à promoção, preservação, manutenção e conservação do patrimônio cultural do município. (IEPHA, s/d)

Diante da impossibilidade de tratar, exclusivamente nesse estudo, as especificidades de cada uma das pastas e atendendo ao objetivo específico desse artigo, na próxima seção será tratado o processo de educação para o patrimônio cultural, definido como um processo educativo voltado para o reconhecimento, a valorização e a preservação do patrimônio cultural.

O programa "ICMS - Patrimônio Cultural" foi premiado pelo Instituto do Patrimônio Histórico e Artístico Nacional (IPHAN) em 2002 e também foi reconhecido pelo Fundo das Nações Unidas para a Criança e o Adolescente (UNICEF), como o melhor programa de distribuição de renda do Brasil. Além disso, destaca-se que desde a criação da política pública de preservação, o IEPHA vem formando, no Estado de Minas Gerais, um banco de dados valioso e fonte de informação para pesquisas referentes à temática da preservação do patrimônio cultural.

\section{Sobre o processo de educação para o Patrimônio Cultural}

Antes de se abordar, especificamente, as questões do processo de educação para o patrimônio cultural, adiante denominado simplesmente educação patrimonial, torna-se relevante apresentar, mesmo que sucintamente, aquilo que se compreende como educação. Para tanto, parte-se dos conceitos de educação formal, não formal e informal.

A educação formal caracteriza-se por ser estruturada e por se desenvolver no seio de instituições, tais como: escolas e universidades, onde o aluno deve seguir um programa pré-determinado. $\mathrm{Na}$ concepção de Von Simson, Park e Fernandes (2001), a educação formal 
tem o caráter compulsório e a responsabilidade de transmitir determinados conteúdos, assim como, de estar subordinada a uma estrutura hierarquizada e a um poder centralizado.

A educação não formal processa-se fora da esfera escolar e é veiculada pelos museus, meios de comunicação e outras instituições que organizam eventos das mais diversas ordens, tais como: cursos livres, feiras e encontros. A aprendizagem não formal desenvolve-se de acordo com os desejos do indivíduo, num clima especialmente concebido para se tornar agradável. Para as autoras citadas anteriormente, a educação não formal não é obrigatória, os conteúdos são os mais variados e não existem conteúdos obrigatórios. Nessa modalidade ao definir-se atividades e conteúdos deve-se voltar para as necessidades e desejos expressos pelo grupo com o qual se irá trabalhar. Ainda segundo as autoras, a estrutura organizacional da educação não formal é bastante flexível e pouco hierarquizada e as formas de participação são descentralizadas e pouco formalizadas (VON SIMSON; PARK; FERNANDES, 2001).

Por sua vez, a educação informal é aquela que ocorre de forma espontânea, no cotidiano, por meio de conversas e vivências com familiares, amigos, colegas e interlocutores ocasionais. Nas palavras de Ebenezer Menezes e Thais Santos a educação informal é:

Termo atribuído à educação desenvolvida fora dos estabelecimentos de ensino ou que ocorre sem planejamento. Geralmente, é um tipo de educação que transcorre em espaços de atividades culturais, com a família, amigos ou grupos de interesse comum. Uma característica marcante dessa educação é a aparente naturalidade do processo, ocultando valores, signos e até preconceitos. No entanto, os meios educativos informais exercem grande influência na formação dos indivíduos. (MENEZES; SANTOS, 2001, s/p)

Focando a atenção naquilo que se propõe nessa seção, todo indivíduo, a partir da educação, deve criar sua identidade pessoal relacionada com o contexto cultural no qual está inserido, conforme disse Flávio Carsalade (2002, p. 68):

(...) apenas com a construção de parâmetros pessoais e de autonomia, inseridos em determinado contexto geográfico, histórico e social, o ser humano pode, efetivamente, educar-se e usar a educação para o crescimento da sociedade em que vive (...).

A partir desse ponto e considerando que o patrimônio cultural é também a materialização da cultura na qual se insere o aprendiz, pode-se estabelecer fortes relações entre a educação e o patrimônio cultural, assim como, pode-se dizer que a educação patrimonial é o amálgama que os une.

Ações educativas ou sensibilizadoras das comunidades detentoras de bens culturais ocorrem desde a criação do IPHAN, em 1937. Mário de Andrade, em seu projeto apontava para a importância do caráter pedagógico dos museus. Rodrigo Melo Franco de Andrade, diretor do IPHAN na década de 1960, destacou a importância da educação pelas palavras: "Em verdade, só há um meio eficaz de assegurar a defesa permanente do patrimônio de arte e de história do país: é o da educação popular". Posteriormente, na década de 1970, sob o comando de Aloísio de Magalhães, a questão foi abordada de maneira mais contundente e o lema de atuação passou a ser sintetizado pela frase:" a comunidade é a melhor guardiã do seu patrimônio”.

Todavia, a expressão educação patrimonial foi introduzida no Brasil, em 
termos conceituais e práticos, por ocasião do $I^{\circ}$ Seminário de Educação Patrimonial, realizado no Museu Imperial de Petrópolis (RJ), inspirado no trabalho educacional que vinha sendo desenvolvido na Inglaterra com o nome de "Heritage Education".

A educação patrimonial é um trabalho permanente de envolvimento de todos os segmentos que compõem a comunidade, visando à preservação dos marcos e manifestações culturais, compartilhando responsabilidades e esclarecendo dúvidas, conceitos e, ao mesmo tempo, divulgando trabalhos técnicos pertinentes e seus resultados. Visa principalmente fortalecer a autoestima das comunidades pelo reconhecimento e valorização de sua cultura e de seus produtos. Esse processo educacional formal e não formal usa situações e ações que provocam reações, interesse, questionamentos e reflexões sobre o significado e valor dos acervos culturais e sua manutenção e preservação. Nas palavras de Maria de Lourdes Parreiras Horta:

A Educação Patrimonial é um instrumento de alfabetização cultural que possibilita ao indivíduo fazer a leitura do mundo que o rodeia, levando-o à compreensão do universo sociocultural e da trajetória histórico-temporal em que está inserido. Este processo leva ao reforço da autoestima dos indivíduos e comunidades e à valorização da cultura brasileira, compreendida como múltipla e plural (HORTA et al., 1999, p. 6)

No que tange a política pública do Estado de Minas Gerais, a Deliberação CONEP Nº3/2017 define que os processos de educação patrimonial devem considerar a democratização do conhecimento em seu alcance e diversidade, promover o diálogo permanente entre os agentes culturais e sociais e a participação efetiva das comunidades detentoras e produtoras das referências culturais.

Dentre os princípios e diretrizes sugeridas para as ações de educação patrimonial destacam-se: (i) implementar uma postura educativa em todas as ações institucionais; (ii) firmar parcerias para realizar programas que estreitem o diálogo com a sociedade sobre políticas de identificação, reconhecimento, proteção e promoção do patrimônio cultural; (iii) promover a participação efetiva da comunidade na formulação, implementação e execução das atividades propostas; (iv) implementar programas que contemplem bens culturais inseridos e associados à vida cotidiana da comunidade; (v) promover a educação patrimonial como processo de mediação; (vi) contemplar os diversos territórios como espaços educativos; e (vii) implementar programas que contemplem a intersetorialidade das políticas públicas. (CONEP, 2017)

Como metodologia de trabalho, a fim de implementar uma postura educativa pautada no patrimônio cultural, os municípios podem executar projetos de intervenção, formação, seminários, rodas de conversa, fóruns, abertos ao público geral ou a grupos específicos da comunidade local, como por exemplo: terceira idade, jovens em vulnerabilidade social, detentos, pessoas com necessidades especiais, gestores municipais, militares, etc. Dentre os eixos temáticos que podem ser contemplados destacam-se: o patrimônio cultural material e imaterial; a história; a memória; a identidade e a cultura.

Dessa forma, a partir desses eixos temáticos, os municípios podem promover ações integradas de educação patrimonial com ênfase nos processos culturais, seus produtos e suas manifestações. Os municípios podem ainda desenvolver e/ou executar uma ou mais ações educativas, de acordo com o demonstrado a seguir: 


\begin{tabular}{|c|c|c|c|}
\hline Área & Ação & Evento & Público \\
\hline $\begin{array}{l}\text { Setor } \\
\text { Municipal de } \\
\text { Patrimônio } \\
\text { Cultural }\end{array}$ & $\begin{array}{l}\text { Promoção de formação } \\
\text { e do envolvimento da } \\
\text { comunidade local. }\end{array}$ & $\begin{array}{l}\text { Seminários, fóruns, } \\
\text { debates, consultas } \\
\text { públicas, projetos, etc. }\end{array}$ & $\begin{array}{l}\text { Servidores municipais, } \\
\text { conselheiros, membros } \\
\text { de associações culturais, } \\
\text { professores, grupos } \\
\text { artísticos. }\end{array}$ \\
\hline Escolas & $\begin{array}{l}\text { Promoção de formação e do } \\
\text { envolvimento das comunidades } \\
\text { escolares e inserção da } \\
\text { educação patrimonial no } \\
\text { currículo escolar. }\end{array}$ & $\begin{array}{l}\text { Seminários, fóruns, } \\
\text { debates, projetos e } \\
\text { adesão ao programa } \\
\text { "Mais Educação" }\end{array}$ & $\begin{array}{l}\text { Corpos discentes, docen- } \\
\text { tes e demais servidores } \\
\text { das comunidades escola- } \\
\text { res de ensino fundamen- } \\
\text { tal, médio e superior. }\end{array}$ \\
\hline $\begin{array}{l}\text { Casas de } \\
\text { Memória "'I }\end{array}$ & $\begin{array}{l}\text { Implementação de projetos } \\
\text { temáticos voltados para a } \\
\text { população geral e/ou para } \\
\text { grupos específicos da } \\
\text { população local. }\end{array}$ & $\begin{array}{l}\text { Seminários, fóruns, } \\
\text { debates, projetos, etc. }\end{array}$ & $\begin{array}{l}\text { Mediadores de locais de } \\
\text { memória coletiva, técni- } \\
\text { cos, agentes culturais, } \\
\text { estagiários, } \\
\text { educadores, grupos } \\
\text { específicos da população. }\end{array}$ \\
\hline $\begin{array}{l}\text { Obras de } \\
\text { conservação } \\
\text { e restauração }\end{array}$ & $\begin{array}{l}\text { Implementação e desenvolvi- } \\
\text { mento de projetos que visem } \\
\text { ao reconhecimento e à } \\
\text { apropriação do bem cultural } \\
\text { por parte da comunidade local. }\end{array}$ & $\begin{array}{l}\text { Ações de conservação e } \\
\text { restauração de bens } \\
\text { protegidos por tombamen- } \\
\text { to e por outras formas de } \\
\text { acautelamento. }\end{array}$ & $\begin{array}{l}\text { Comunidade em } \\
\text { geral ou grupos } \\
\text { específicos da } \\
\text { população. }\end{array}$ \\
\hline
\end{tabular}

FONTE: DELIBERAÇÃO CONEP № 03/2017 - ADAPTADO

Em se tratando de trabalhos voltados para a educação formal, salienta-se que antes de se iniciar um trabalho de educação patrimonial devem estar bem definidos os objetivos educacionais e os resultados esperados com a atividade. $\mathrm{O}$ educador deverá estar atento às habilidades, conceitos e conhecimentos que a atividade desenvolverá nos educandos, assim como deverá saber de que modo as atividades se inserem no currículo escolar.

A educação patrimonial possui as seguintes etapas de trabalho: Observação; Registro; Exploração e Apropriação. O quadro abaixo, sintetiza cada uma das etapas, apresentando os objetivos e sugerindo uma metodologia. 


\begin{tabular}{|l|l|l|}
\hline \multicolumn{1}{|c|}{ Etapa } & \multicolumn{1}{|c|}{ Objetivos } & \multicolumn{1}{c|}{ Metodologia } \\
\hline Observação & $\begin{array}{l}\text { Identificar o objeto/função/significado; } \\
\text { Desenvolver a percepção visual e } \\
\text { simbólica. }\end{array}$ & $\begin{array}{l}\text { Utilização de jogos de memória, desenhos, } \\
\text { jogos dos sete erros, jogos de comparação } \\
\text { com fotos antigas e recentes, perguntas etc. }\end{array}$ \\
\hline Registro & $\begin{array}{l}\text { Fixar o conhecimento percebido; } \\
\text { aprofundar a observação e análise crítica; } \\
\text { desenvolver a memória, o pensamento } \\
\text { lógico, intuitivo e operacional. }\end{array}$ & $\begin{array}{l}\text { Desenvolvimento de redação, desenho, } \\
\text { poesia, explicação verbal, fotografias } \\
\text { (produção e análise), maquetes, plantas } \\
\text { e mapas. }\end{array}$ \\
\hline Exploração & $\begin{array}{l}\text { Desenvolver a capacidade de análise } \\
\text { e julgamento crítico;aprender a } \\
\text { interpretar os fatos e acontecimen- } \\
\text { tos; descobrir significados. }\end{array}$ & $\begin{array}{l}\text { Discussão com os alunos ou grupo sobre } \\
\text { conceitos, dúvidas; desenvolvimento de } \\
\text { trabalhos sobre o tema através de entrevis- } \\
\text { tas, pesquisa em livros, revistas, jornais e } \\
\text { internet. }\end{array}$ \\
\hline Apropriação & $\begin{array}{l}\text { Envolver afetivamente os educandos } \\
\text { com o objeto cultural; apropriar-se do } \\
\text { bem como patrimônio cultural; valorizar } \\
\text { a cultura local. }\end{array}$ & $\begin{array}{l}\text { Identificação do que cada um aprendeu com } \\
\text { os trabalhos do projeto. Este é o momento } \\
\text { que o grupo tem para expressar, da maneira } \\
\text { que for mais conveniente, o significado da } \\
\text { atividade educativa para cada um. }\end{array}$ \\
\hline
\end{tabular}

Quadro - Etapas da Educação Patrimonial

FONTE: HORTA, 1999 - ADAPTADO

A educação patrimonial para além de ser "um instrumento de alfabetização cultural, que possibilita ao indivíduo fazer a leitura do mundo que o rodeia, levando-o à compreensão do universo sociocultural e da trajetória histórico-temporal em que está inserido" (HORTA, 1999, p. 6), é também um princípio jurídico. Como tal, figura na Constituição Federal, como imposição expressa, e faz parte das ações do Ministério Público como pode ser percebido na obra intitulada - "Princípios Básicos da Proteção ao Patrimônio Cultural", de autoria do Professor e Promotor de Justiça do Ministério Público do Estado de Minas Gerais Dr. Marcos Paulo de Souza Miranda, que traz:

Na "Carta de Goiânia" - $1^{\circ}$ Encontro Nacional do Ministério Público na Defesa do Patrimônio Cultural ficou consignado na conclusão de $n^{\circ} 04$ : Só por meio da educação é possível mudar valores e incluir a preservação do Patrimônio Cultural na rotina de vida dos cidadãos. É preciso que as instituições de cultura, educação e a sociedade em geral incluam a educação sobre o patrimônio em seus projetos. É necessário criar essa "consciência cultural", pois a condição primária para a preservação de um bem cultural é o reconhecimento de seu valor pela comunidade onde está inserido. (MIRANDA, 2009, p. 21-22).

Dessa forma, encerra-se essa seção reforçando a crença de que a educação tem papel fundamental na estruturação, na consolidação, e no destino de uma sociedade. Parafraseando o célebre educador Paulo Freire, a educação de homens se dá pelo contato de uns com os outros, intermediada pelo mundo que os cerca. 


\section{Considerações finais}

O pluralismo democrático estabelecido após a promulgação da Constituição Federal, em 1988, reflete e respalda a diversidade cultural brasileira e, ao mesmo tempo, permite que diferentes grupos sociais acessem o poder. Tal condição, ao consentir a manifestação de diferentes práticas culturais, respalda novas referências.

Proteger nossas referências culturais implica em ir além do estabelecimento de dispositivos jurídicos, requer o (re)conhecimento por meio de ações educativas. Não há dúvida que incrementar e enaltecer os aspectos culturais de uma sociedade são ações de extrema relevância, da mesma forma que a participação popular ainda é a melhor maneira, e a mais democrática, para tentar melhorar as condições de vida de todos. Mas, para que se tenha resultados que atendam satisfatoriamente à maior parte da população, é necessário que esta mesma população esteja capacitada para opinar, coerentemente, sobre as ações a serem implementadas.

Diante do exposto, salienta-se que toda produção cultural deve ser valorizada independentemente da riqueza ou pobreza da região que a produz. Assim, primeiramente, se deve reconhecer o caráter democrático da política pública do Estado de Minas Gerais que vem permitindo, tanto aos municípios mais ricos quanto aos mais pobres, receberem recursos financeiros de maneira um pouco mais justa e, em especial, por destinar, mesmo que por uma parcela mínima, recursos para proteger o patrimônio cultural do Estado.

Acredita-se que uma política pública, em particular uma política de preservação cultural, só se mostra correta e consequente quando, além de contemplar medidas referentes à memória de um povo, baseia-se mais amplamen- te em uma concepção que integra as questões socioeconômicas, técnicas, artísticas e ambientais, articulando-as com as questões de qualidade de vida, meio ambiente e cidadania. A integração do patrimônio cultural ao cotidiano das pessoas e às suas celebrações faz com que este exerça sua força geradora de identidade étnica, de valorização ética e de referência.

Malgrado o exposto, para uma sociedade que se pretenda democrática de direito, não basta o princípio participativo, muitas vezes manipulado por meia dúzia de detentores do saber, se faz necessário "combater a pobreza". Esta, entendida não como a falta de recursos financeiros, mas como a falta de discernimento, empoderamento e capacidade de opinar e criticar, positiva ou negativamente, uma determinada situação que diz respeito à vida dos cidadãos. Para tanto, sugere-se reforço no tratamento das políticas públicas, principalmente, de educação e cultura, pois se acredita que estas são as responsáveis por moldar e dar oportunidades aos indivíduos.

\section{Bibliografia}

BRASIL. Presidência da República. Constituição Federal de 1988. Disponível em: <http://www.planalto.gov.br/ccivil_03/constituicao.htm>. Acesso em: 18 jan. 2017.

CARSALADE, F. de L. Educação e Patrimônio Cultural. In: MINAS GERAIS. Secretaria de Estado da Educação. Reflexões e Contribuições para a Educação Patrimonial. Belo Horizonte: SEE/MG, 2002.

CONEP. Deliberação Normativa. Instituto Estadual do Patrimônio Histórico e Artístico de Minas Gerais, 2017. Disponível em: <http://www.iepha. mg.gov.br>. Acesso em: 13 jan.2017. 
FUNDAÇÃO JOÃO PINHEIRO. Histórico da Lei Robin Hood. Fundação João Pinheiro. Centro de Estudo de Políticas Públicas. Belo Horizonte: 2010. Disponível em: http://200.198.50.36/robin-hood/index.php/leirobinhood/historico. Acesso em: 15 de ago. 2017.

FUNDAÇÃO JOÃO PINHEIRO. Manual da Lei 18.030 - Robin Hood. Fundação João Pinheiro. Centro de Estudo de Políticas Públicas. Belo Horizonte: 2009. Disponível em: http://200.198.50.36/ robin-hood/index.php/leirobinhood/manual. Acesso em: 15 de ago. 2017.

HORTA, M. L. P.; FARIAS. P.; GRUNBERG, E.; MONTEIRO, A. Q. Guia básico de educação patrimonial. Brasília: Instituto do Patrimônio Histórico e Artístico Nacional, Museu Imperial, 1999.

IEPHA. 40 anos na proteção do patrimônio cultural mineiro. Disponível em: <http://www.iepha.mg.gov. br>. Acesso em: 13 jan. 2017.

MAGALHÃES, A. E triunfo? A questão dos bens culturais no Brasil. Rio de Janeiro: Fundação Roberto Marinho/Nova Fronteira, 1997.

MENEZES, E. T. de; SANTOS, T. H. dos. Verbete educação informal. Dicionário Interativo da Educação Brasileira - Educabrasil. São Paulo: Midiamix, 2001. Disponível em: <http://www.educabrasil.com.br/educacao-informal/>. Acesso em: 15 de ago. 2017.

MINAS GERAIS. Assembleia Legislativa. Constituição do Estado de Minas Gerais de 21 de setembro de 1989. Disponível em: <http://www.almg.gov. br/consulte/legislacao>. Acesso em: 13 jan. 2017.

MINAS GERAIS. Assembleia Legislativa. Lei $n^{\circ}$ 12.040 de 28 de dezembro de 1995. Disponível em: <http://www.almg.gov.br/consulte/legislacao>. Acesso em: 13 jan. 2017.

MINAS GERAIS. Assembleia Legislativa. Lei $n^{\circ}$ 13.803 de 12 de janeiro de 2009. Disponível em: <http://www.almg.gov.br/consulte/legislacao>. Acesso em: 13 jan. 2017.

MIRANDA, M. P. de S. Mestres e Conselheiros: Manual de atuação dos agentes do Patrimônio Cultural. Org. Marcos Paulo de Souza Miranda, Guilherme Maciel Araújo e Jorge Abdo Askar. Belo Horizonte: IEDS, 2009.

VON SIMSON, O. R. de M.; PARK, M. B.; FERNANDES, R. S. Educação não formal: cenários de criação. Campinas, SP: Editora da UNICAMP, Centro de Memória, 2001.

\section{Recebido em 22/12/2017 Aprovado em 26/02/2018}

I Clésio Barbosa Lemos Júnior, Arquiteto Urbanista, doutor em Geografia Urbana pela Universidade Estadual de Campinas, professor da Faculdade de Arquitetura e Urbanismo do Centro Universitário de Formiga, em Minas Gerais. Contato: clesio1804@gmail.com

II Fundação João Pinheiro. Disponível em: <http://www. fjp.mg.gov.br/robin-hood/index.php/leirobinhood/historico>. Acesso em: 11/08/2017.

III São entendidas como Casas de Memória os arquivos, os museus, as bibliotecas, as comunidades tradicionais e afins. 